\title{
AN ANALYSIS OF MELINDA'S STRUGGLE IN SELF-EXPRESSION DURING TRAUMATIC CONDITION IN "SPEAK" MOVIE
}

\author{
Budiarto $^{1}$ \\ Sekolah Tinggi Bahasa Asing IEC Jakarta \\ budiarto@stibaiec-jakarta.ac.id \\ Nurul Lia Ahmadi \\ nurulliaa@stibaiec-jakarta.ac.id \\ Sekolah Tinggi Bahasa Asing IEC Jakarta \\ Suhendar \\ suhendar@stibaiec-jakarta.ac.id \\ Sekolah Tinggi Bahasa Asing IEC Jakarta \\ Mangantar Sitohang \\ Sekolah Tinggi Bahasa Asing IEC Jakarta \\ mangantar@stibaiec-jakarta.ac.id
}

\begin{abstract}
Budiarto, Ahmadi, N.L., Suhendar and Mangantar, S. (2022). An Analysis of Melinda's Struggle in SelfExpression During Traumatic Condition in SPEAK movie. Journal of English Language and literature, 7(1), 85-98. doi: 10.37110/jell.v7i1.146
\end{abstract}

Received: 02-02-2022

Accepted: 25-02-2022

Published:03-03-2022

Abstract : In this research, the researcher analysis a movie entitled Speak. This movie tells about a young girl who suffered from traumatic experiences during her adolescence because of being rape victim. As a result, she can't express herself and can't communication with others comfortably. The aims of this research are to analyze and to explain the trauma that face by the main character, and her struggle to recover with it. The researcher uses the theory of Post-traumatic Stress Disorder, selfexpression, and art therapy to analyze this research. This analysis shows that the main character of this movie is in a bad condition that is reflected to her daily activities. She suffers from guilt, shame, depression, losing concentrate and self-confidence. But finally, she can find the way to heal from her trauma through art class and speak the truth to the people.

Keywords: Post-traumatic stress disorder, PTSD symptoms, communication, art therapy

\section{INTRODUCTION}

Throughout their lives, people create a variety of memories. Memories have an indirect impact on how people live and communicate with others.
Memories can be beautiful or painful. A movie about a girl who experience from bad memories after being raped when she attended a party on a summer night, and no one knows about the incident.

${ }^{1}$ Corresponding Author 
That's movie is entitled Speak. Since then, Melinda has to face the horrific experience and get bullied by her friends. Enters high school, she tells the story of the terrible event of her life. She keeps silent, and unable to deliver her feeling with confident. Speaking has become a burden to her. She had no other way of expressing her pain and also always avoiding situations. It's because of the traumatic event that she suffered. And it also has any impacts on her personality, behavior, action, and other things. No one likes her and many people avoided her. She is lost everything, all the connection with the outside world. Because she won't speak or communicate with anyone. Melinda struggles to find back her expression, and overcome her trauma while gets motivation from her teacher and gets her self-confidence back through art class.

Communication always has an element of risk. It will impact to other people who receive what you are saying. It may feel afraid to say what we want. Even though, we want to communicate. All forms of self-expression are "risky". We have no idea. The important thing is, you should learn how to express yourself. The term self-expression means to the action of expressing people's thoughts and emotions through words, choices, or actions (Kim \& Ko, 2007). Because, people are expected to communicate themselves as much as possible. For example, through art. Through art, you can find and show your self-expression. It is the same as a movie that I analyze. Melinda slowly expresses her burden through art class. She struggles to relieve the trauma because it is the most crucial conflict of the main character must face. She also gets motivated to try and to build her self-confidence that the only way to attack evil is to speak out about it. According to Breitbart, stated that life is full with struggle, and it enhances our lives (2016). Recognizing that life is a struggle helps us to confront life head on and work and love realistically. Motivation has related to struggle. People frequently have motives or aims for what they believe or do through their actions. This action is called as a struggle and the reasons and the goals are calls as motivation. Human behavior is greatly influenced by the concept of motivation. Individuals' effectiveness and efficiency are enhanced by using motivational factors. As a result, both individually and in a group achievements have already been made. The concept of motivation has caught scientists' interest from every fields concerned with humans. As a result of the study, various ideas have been established and described. Moos, Wright, et al stated that motivation can be considered to influence and direct human behavior, as well as contribute to assuring cohesion (2010;2007).

Motivation is necessary for someone who wants to build self-confidence and to struggle to express herself. Self-confidence is appearing when people already tried to struggle and to get motivated. According to Ekinci, It has been argued that a human's sense of self-confidence is a critical factor in having a positive life, developing one's own abilities, and utilizing one's positive characteristics in order to be a successful person. (2013). It is connected to the self-confidence of those who are very motivated to accomplish something since a person with a lack of confidence will avoid making effort to reach their goals. The struggle is one thing that we cannot avoid in life. People should struggle in order to achieve goals or make a good life. Each person has their own struggle in continuing their life.

The study discovered that the idea of art and it has a relationship with self-expression. As a nonverbal and experiential treatment, art therapy emphasized visuals rather than words, and gives a different kind type of connection to traumatic thoughts and emotions than oral treatments. This treatment may benefit for patients who are scared to talk about their traumatic or unable to withstand exposure treatments. It means that we can use art as imagination to express our feeling, ambitions, and issues that may develop in our life. The artwork' aim was uncertain; however it's assumed that people played a role of communication and displayed numerous customs. Aubert, et al, they stated that 
according to some anthropologists and archaeologists believe that cave art may have also expressing hunting and gathering concepts, to support the concept that sketching and other art forms can be utilize as a form of self-expression (2014).

Other research has indicated that, based on psychological theory, self-expression is one of the most highly respected and venerated qualities in Western civilization, due to the society's neardeification of "the human". Self-expression is not only an important part of Western society, but it is also established in psychology's foundations. Psychology is the study of the mind, which involves oneself, others, and groups of people. We learn about the mind by observing people's expressions, whether verbal or nonverbal. (Kim\& Ko, 2007). That's why we should learn to communicate because most of us have communication problems. After all, some are introverted, unconfident, or simply lack confidence in our ability to communicate. Learning to communicate is the key and the important thing for someone to interact with others in their world. Communication also helps to removing misunderstandings among people and creating clarity of thoughts and expressions. You will be gaining the skills to understand and express it. You can express yourself in many ways, such as yelling to express your feelings about what you feel, or you can express your feeling through art, music, write a poem, etc.

The aim of the previous researcher related to this topic is to put the meaning and practice of selfexpression into context to learn why someone use or don't use certain types of self-expression, and why self-expression affects people the way it does. It also intends to examine the psychological implications of self-expression from a more multicultural perspective. (Kim \& Ko, 2007).

To fill the gap, the research is intended to focus on the main character in the movie speak. The researcher writes this research to find out the main character's struggle to express herself through art class and her surroundings. The researcher hopes that the readers will understand well how they will express themselves in a good way. And also to respect those who can't express themselves and just being silent. Because it is their right whether they open their mouth to express themselves or not.

\section{REVIEW OF LITERATURE}

\section{Struggle}

Many experts are attempting to define struggle in many aspect. Some of them are Exline, Pargament, Grubbs, \& Yali (2014), Marsam (2000), Badaracco (2013), and many others that the researcher cannot mention one by one.

According to Exline, Pargament, Grubbs, \& Yali, they define Struggle with ultimate purpose is defined as the distress and internal conflict that arises from fears that life may lack a deeper purpose or that existence may lack an underlying significance, that is, a struggle in which concern centered on a perceived lack of deep meaning in life (2014:209). Marsam defined that The word struggle is derived from the word struggle, which indicates a war for survival or state independence (2000:181).

$\mathrm{He}$ added that the struggle in his research implies, as a feminist, to oppression, by a substantial cultural flourishing in society. His view also means that struggle is hard work and commitment as the secret to success in achieving a good thing.

Badaracco tried to give a conclusion that whether it's a good or bad struggle is not depending on whether the purpose is to overcome bad or to accomplish good, whether the object one is attempting to achieve or maintain is regarded good or bad is another matter (2013).

From the above quotations, it can be summarized that Struggle is the distress and internal conflict around yourself and you have to fight for survival. And the struggle does not have to be physical, it may also be psychological that related not only external forces but also internal, such as one's own evil thought. Although a struggle is bad but It makes 
no difference whether the purpose is to defeat the bad or to accomplish the good.

\section{Struggle for Life}

People face problem's difficulty in their life. There are numerous problems that can occur, it can be easy or complicated. The struggle occurs when someone going through temptation and tries to get out of their problems to get something and struggle to get it by against difficulties and try hard until all is achieved. The meaning of struggle as the key to success, struggle is long process and attempts in accomplishing a wonderful thing. One of the reasons that people wanted to maintain their lives is because of struggle. According to Chittister, stated struggle is an important aspect of life. Struggle is a necessary part of life (2005)

Human usually utilizes a few techniques to protect their ego. They can fight with their repression, perception, rejection, and intellectualization. They can take positive lessons from their struggles. Everyone is aware of this that they need to struggle because they will be satisfied by their effort. Thus it is necessary to struggle for life to achieve the goal of life and overcome the problems of life.

\section{Motivation}

For students' behavior, motivation is an important factor. It can be claimed that when a student's motivation is great, the chances of the student's success will increase. As a result, we need to struggle to find a plan to support you in getting started.

According to Elliot and Dweck, throughout childhood and adolescence, motivation is an important factor in academic learning and accomplishment (2005). It has a significant impact on student progress.

Moos \& Marroquin; Wright \& Wiediger, they pointed out that motivation impacts and directs behavior, as well as assuring continuity (2010;2007). The idea of motivation has a significant impact on human behavior. Individuals' effectiveness and efficiency are improved by using motivational factors. As a result, individual and group achievements have been made.

It is stated that students' motivation has a significant impact on their academic progress. (Maulana, Opdenaker, den Brok, \& Bosker, 2011; Ozen 2017). Therefore as result, it's critical to figure out what motivates students.

From the above quotations, it can be concluded that Motivation is important for the children and adolescence in their academic learning, it also influence their behavior in the academic progress.

\section{Types of Motivation}

Personality studies have revealed that each person has a unique set of personality traits that influence their emotions, perceptions, feelings, thoughts, and motivations. Different perspectives on motivation have been presented by psychologists, including determining whether An individual's motivation might come from the outside (extrinsic) or from the inside (intrinsic).

Researchers found out that each form has a distinct impact on a person's behavior and achievement. It will be beneficial to comprehend how each form of motivation works to better comprehend the impact of intrinsic and extrinsic motivation on human behavior.

People have different views not just in terms of the quantity of motivation they have, but also in terms of the kind of motivation they have. Sans and Harackiewicz stated that the argument between intrinsic and extrinsic motivation began in the 1970s, when several studies examined into the validity of extrinsic and intrinsic motivation (2000). There are two types of motivation, including:

\section{Intrinsic Motivation}

In psychologicily terms, Internal and external rewards are defined as intrinsic motivation. In "Introduction to Psychology: Gateways to Mind and Behavior With Concept Maps, Coon and Mitterer defined that when we behave without expecting anything in return, we are said to be self-motivated, 
this is known as intrinsic motivation. We either like a specific activity or see it as a chance to learn, develop, and achieve our full potential (2010). Intrinsic motivation is defined as doing something just for the sake it is intrinsically interesting or exciting.

Seeing as intrinsic motivation occurs at the nexus of a person and a task, some experts define it as how engaging the task is, while others describe it relating to the benefits an individual gains through intrinsically motivated task performance. Intrinsic motivation is a human desire that is most usually characterized as doing something for its own sake.

\section{Extrinsic Motivation}

Extrinsic motivation is defined as behavior that is motivated by rewards from outside sources. These gains can be financial or educational in nature, or intangible in nature, such as recognition or celebrity. External factors are the only source of extrinsic motivation.

According to Tranquillo, he defined that extrinsic motivation occurs when we are motivated to perform a task or engage in an activity in order to obtain a reward or avoiding consequence (2016). You will interact in behavior not because you enjoy or find it fascinating, but since you expect to receive anything in exchange for something or a way to avoid something undesirable.

The Relationship Between Motivation and SelfConfidence

It has been shown that self-confidence is a crucial aspect in conducting a positive life, developing one's own abilities, and maximising one's positive attributes in order to be someone who is successful (Ekinci, 2013). It is connected to the self-confidence of people which are highly motivated to work, because those who have selfdoubt avoid putting up the action required to achieve their targets (Ekinci, 2013).

Self-confidence is described as a person's belief in someone intalents, In school, as well as in personal and social life, knowledge, authority, and choices play a significant role. Extrinsic selfconfidence is the ability to express oneself, communicate, and control one's emotions, and it is the picture and external impressions world as being self-confidence(Bilgin,2011).

Motivation is the structure that forces an organism to respond, determines the consistency and regularity of these actions, and provides various external and internal factors which can lead to behavior and actions, as well as the coordination of these behaviors and actions. (K1lınç, Ulucan, Kaya and Türkçapar, 2012). It means that Extrinsic and intrinsic motivation define external factors like reward, and intrinsic motivation such as interest, desire, and need, while extrinsic motivation is defined as something that comes from within people. (Öncü, 2003).

So, Self-confidence is fundamental to psychological motivation studies. (Bandura, 1997, Eccles, 2009) and has use in education: selfconfidence of students have been linked to their enthusiasm in specific courses. (Viljaranta, Tolvanen, Aunola, \& Nurmi, 2014), as an example, and in terms of the subjects they choose to study (Regan and Dewitt, 2005). It means that selfconfidence is a contributing factor of achievement motivation students; teachers may be trained to enhance their achievement motivation. So that, it builds up high self-confidence. By promoting achievement motivation, the self confidence of the individuals can be enhanced. Teachers could assist students in lowering sentiments of failure in order to boost their self-confidence. As a result, teachers and parents should ensure that students are confident in themselves and perform much better in their daily lives.

\section{Self-Expression}

A concept of one's own personality characteristics, thoughts, or feelings is known as self-expression. (Kim \& Chu 2011). He added that self-expression is a concept that is intimately connected with optimistic theorys, such as style, courage, freedom, creativity, self-assurance, and even remedial and 
religious studies. Thus, people are requred to articulate themselves at any time possible, and Selfexpression is expected to be advantageous and beneficial in the long term.

According to Plume and Slade, they stated that a reward for expressing oneself and exchanging individual expression with others is characterized as self-expression. (2018).

Self-expression is to distinguish the topic from processes in which words represent ideas or concepts and phrases express arguments". (Green, 2010)

From the above definitions, the researcher concludes that Self-expression is defined as a reward for expressing the ideas or feelings, in which words express ideas or concepts.

\section{Ways of Self-Expression}

The one has different ways to express themselves. They can express themselves whether through speech, writing, or action. Lots of other people agree that performing in creative activities is a great way to express yourself. But, for those who think that through expressive play, art, and Dealing with difficult emotions is considerably simpler when you write about them than through thinking or talking about it. Because they do not use any words to express themselves. Therefore, studies showed that people express themselves in a number of different ways, one of which is because of to their choices (Aaker \& Schmitt, 2001; Kim \& Drolet, 2003; Snibbe \& Markus, 2005; Tafarodi, Mehranvar, Panton, \& Milne, 2002).

According to Rogers, as a therapist who helps people express themselves, he uses dance, art, painting, song, led imagination, relaxation, and verbal and non verbal communication abilitiess, and guided fantasy to help with individual awareness, self-expression, and highly elevated levels of awareness. Dance therapy, art therapy, and music therapy are examples of nonverbal therapies called as " Therapuetic expression " or "expressive arts therapies." This word also include writing, acting, and improvisational theater as forms of therapy.
And here are some ways to express yourself, as follow:

\section{Writing}

One has to understand the purpose of expressing thoughts, feelings and, emotions instead of simply sending messages. In addition, Writing dialogue journals encourages individuals to write and take risks when expressing themselves. (Mansor, Shafie, Maesin, Nayan, and Osman, 2011). You must feel free and not anxious if you already started writing something. At first, it will become anxious, timid, so afraid that you may put something down that is not good as Shakespeare. It is claimed that expressive writing can allow somebody to explore and express his personal experience, his opinion about things, his reactions to the world. Therefore, you can find someone who is good at teaching. And those someones are your friends who love you, who think you are interesting, or very important, or wonderfully funny.

\section{Speech}

The popular concept about speech in Western cultures is that it connects into oneself, and they communicate through words, their internal feelings, moods, and ideas that make up their personal identity.

According to (Kim \& Markus, 2002; Kim \& Sherman, 2005), they defined thatSpeech is likely a more significant form of self-expression than choices, and as a result, speech is a main way of expressing one's internal traits in the Western cultural environment, as "expressing somebody's thoughts" is the most efficient way of expressing somebody's thoughts.

\section{Arts}

The arts on which Reid has something to say can be neatly classified into three categories:

Painting and sculpture

Poetry and drama

\section{Music}

Self-expression by music and art is a better platform for inner tensions and feelings and It's been utilized 90 
in treating pain and anti-addiction programs. According to Stuckey and Nobel, they defined that Art allows people to express feelings that are difficult to describe verbally (2010).

\section{Communities}

Communities facilitate the formation of relationships with like-minded people, with a focus on those who share common interests in faith, athletics, or art, as well as the sense of belonging that can result from such interactions. (Cordina, Gannon, \& Croall:2018)

\section{The Importance of Self-Expression}

Self-expression is a key not only for our personal and interpersonal interactions, but also for our work lives. They argue that we discover about ourselves through expressing ourselves, reflecting on our inner selves, and engaging in creative learning activities that will help us in all aspects of our lives, throughout all organizations and perspectives. (Hanes \& Weisman, 2016).

According to Gannon et al., According to study, communitas emerges from shared experiences. (2017). It means that through communitas you will have feelings of togetherness, belonging, and collective harmony among people. And also some people are motivated and get the opportunity to meet new people and have a closer relationship with them. In addition, It will give individuals the opportunity to escape from their ordinary activities and participate in memorable experiences that exceed journey times.

Others said that speech, It's believed to be a true reflection of one's true emotions, ideas, and purposes. Using one's creativity to express oneself is a growth process within itself, although we may attempt to understand our dancing, or painting, is an expression of our deep involvement in the healing process. And another person said, I learned that by expressing or performing my emotions, I have the ability to break down internal boundaries that I had created for my own self. To draw that feeling after the movement continued the process of unfolding (Rogers:1986).

\section{Post-Traumatic Stress Disorder}

PTSD can be characterized as an unpleasant memory that individuals are unable to forget. Patients with PTSD may eventually experience changes in their life, relationships, actions, thoughts, feelings, and attitudes. Patients commonly make comparisons between their life before and after the event. It has the potential to make their emotions run out of control.

Raped, like many other traumatic events, it is a factor causing PTSD. Rape trauma is also unusual because it may be far more terrible than other forms of traumatic. According to the Diagnostic and Statistical Manual of Mental Disorders (5th ed.; DSM-5; American Psychiatric Association, 2013), Intrusive symptoms (flashbacks of the incidents), avoidance behaviors (avoiding persons or situations that recall the victim of their rape), negative cognition or affect changes (e.g., cognitions that the world is an unpleasant place), and hyper-arousal (e.g., being easily startled), those are all signs of PTSD

Positive social support can encourage the victim to accept her experience by offering the meaning, as well as enhance her self-esteem and reassure her that the world isn't all bad. Negative responses from others may cause more suffering and perhaps revictimization. Brewin \& Holmes; Ullman \& Filipas, et al, defined that being blamed for the assault by others can lead to the victim blaming himself or herself and feeling ashamed, both of which are linked to PTSD $(2003 ; 2007)$.

Gray et al., stated that Large decreases in PTSD and depression, as well as significant increases in Post-traumatic growth, are linked to trauma-related disclosure to sources of social support. (2012).

PTSD is a mental illness that can exist with a result of being treated to highly dangerous or terrifying occurrences (Bisson et al., 2015). PTSD can arise as a result of one traumatic experience or through repeated trauma exposure, such as sexual assault as in childhood. Many people obviously 
have a healing period and the ability to heal after being exposed to trauma.

It can be summarized that PTSD as unpleasant memory that may be far more terrible by the victim. They will receive the negative responses from others, and $t$ made them feel guilty and ashamed that turn out to be depression which is an extremely dangerous or terrifying experience.

\section{The Symptoms of Post-Traumatic Stress Disorder}

Trauma exposure is related to PTSD symptoms on a specific basis. And according to The DSM-5, the symptoms of PTSD are divided into four groups, including:

\section{Avoidance}

Avoiding people, places, activities, objects, and situations that remind someone of the traumatic event might lead to avoidance of people, locations, actions, things, and events that may influence bad memories. People might struggle to forget or avoid recalling the terrible incident. They may be eager about not mentioning what happened or how they feel about it.

\section{Intrusive Symptoms}

Intrusive thoughts like repeated, unwanted memories; horrifying nightmares; or flashbacks of the traumatic event. People may have significant flashbacks, leading them to assume they are reliving or experiencing the traumatic event.

\section{Increased Arousal}

Arousal and reactive symptoms may including irritated and unstable to angry outbursts; acting recklessly or identity; being suspiciously overly aware of one's surroundings; being embarrassed, or having difficulty focussing or sleeping.

\section{Alterations in Cognition and Mood}

Inability to recall significant details of the traumatic experience, as well as negative feelings and emotions that lead to permanent and inaccurate ideas about individuals and many others. (e.g., "I am bad person," "Nobody can be depended trusted."); inaccurate ideas about the event's causes or consequences, resulting in inappropriate self- or other-blaming; continuing anxiety, terror, fury, shame, or guilt; very a reduction in interest in pleasurable activity; feeling separated or isolated from others; or inability to have a good feelings (a lack of enjoyment or satisfaaction).

\section{METHOD}

This research, researcher used the qualitative method by employing content analysis and a psychological approach. In the qualitative method, Ary mentioned that the Instead of numerical form, a qualitative inquirer works with data in terms of words or visuals (2010:424). It means that the researcher finds the meaning from all the data that is available. The data can be classified and sorted according to patterns. In general, in the social sciences, the qualitative method was developed to help researchers to analyze social phenomena such as: analyzing emotions, thoughts, and behaviors.

Content analysis refers to the process of analyzing the content of a design of analysis for the movie. This type of the research tries to analyze the data that is available in the script of a movie to understand the content and the meaning of that data. Cole defined that a process of examining written, vocal, or visual communication signals is called as content analysis (1988). It was already employed in the nineteenth century to analyze songs, books and newspapers, ads, and tv interviews (Harwood\&Garry 2003). Additionally, The researcher analyzes the aspect that supported the finding of the meaning in the script.

\section{FINDING AND DISCUSSION}

\section{The reason of the main character can't show her expression}

Melinda's life during her adolescence with the problems she has to cope with in her life. It makes her silent. She finds it difficult to express herself. Especially to have communication with others. It's because of the sexual harassment that she experiences. Melinda was being raped at the party that she attended. Emm, et all, pointed out that as a victim of sexual, communication problems are 
usually reported $(1988 ; 1990)$. Victims may be scared of making the wrong decision, They might want to avoid mentioning the remainder of the harassment, or They might not want to bother the other person with rape-related emotions and thoughts.

Melinda, who is a victim of rape, tried to carry on her life as usual while haunted by the traumatic experience. All of he friends misunderstood her as being the blame who ruin the party and make them in trouble by calling the police. She has become an introvert girl since then, never speaking to anyone. It's because she doesn't trust anyone, and they have no idea that Melinda has been sexually harassed.

Sexual harassment is a serious issue that classified into verbal, non-verbal, and physical sexual harassment. For any purpose, it involves assaulting an individual, touching or massage people without previously obtaining permission to do so on anyone's body. PSTD is a psychological disorder that can emerge after someone has experienced a traumatic event such as sexual harassment. The newest version of the Diagnostic and Statistical Manual of Mental Disorders (DSMIV; American Psychiatric Association, 2000) stated that Posttraumatic stress disorder (PTSD) can develop when a person is dealt with an event that threatens the others' physical integrity, like sexual harassment.

The unexpected events of rape can be caused trauma that leads to silence. Silence is common among rape victims. Raped The victim is always left with a traumatic experience and it reduces a person able to speak. The victim will start living differently. Christiansen, et all, defined that Rape is commonly regarded to be extremely stressful for the victim, with long-term negative consequences (2012). A victim would also feel shame and guilt which debilitate their mental and emotional. It's likely that shame and the fear of negative evaluation from romantic relationships have the same or even greater effect in relationships.
After the rape incident, it causes Melinda to fall into the deepest depression where she cannot enjoy and cannot express her thoughts and feelings. She has no action to express what we called as selfexpression. Post-traumatic stress disorder (PTSD) is a well-known psychiatric condition that can develop in the after of a significant traumatic event. Experiencing phenomena like nightmares and repeated unpleasant Memories of the incident, avoidance and general numbing response like trying not to talk about or be recalled of the trauma, disconnection and rejection from others are all common symptoms and hyperarousal symptoms considering lack of sleep, anxiety, and irritability.

According to Van Westrhenen, Overwhelming emotions of re-experiencing the trauma (nightmares and intrusive ideas), avoidance of trauma causes, unpleasant changes in mood and cognition, there are some of the symptoms of PTSD (2014). People with PTSD will also be forced to face the negative effects of the traumatic event that caused the medical condition, which can cause dramatic changes in cognition and mood, as well as making them avoid trauma-related stimuli at all costs. These symptoms have a significant impact on people's daily lives and work.

People with post-traumatic stress disorder will find it difficult to express themselves because of the pressure that continues to be given by the surrounding environment. It's because Posttraumatic stress disorder (PTSD) is very common because of rape or other forms of sexual harassment. There have been many numerous kinds of trauma that one might go through, and Regardless of whether the trauma is acute or chronic, may induce a wide range of symptoms, which are unique to the individual. Hurlocker et al., he stated that the signs and symptoms of PTSD and psychological distress are similar (2018). People who are burdened by negative feelings are more likely to engage in undesirable activities such as self-blame or avoid situations. Many of the symptoms that appear after rape are covered in the PTSD diagnosis. Similarly, re-experiencing the trauma (nightmares and 93 
flashbacks), avoidance and numbing (avoidance of thoughts and reminders of the trauma), and increased arousal, there are three symptom categories that define PTSD (Sleep and concentration issues, as well as extreme startle reactions).

Melinda suffers from psychological trauma as a consequence of her horrible experience of being sexually harassed, she stays mute and refuses to speak to people. Melinda abruptly stopped communicating and limited the distant from the world around her. Melinda starts skipping school, separates herself from her parents, and loses herself. It's just because she wants to forget all the bad things that happened to her at the summer night. Melinda also tries to avoid its triggers, who cause her having a traumatic event. But, her struggle is in vain, she keeps remember the raped incident and it makes her having a problem in sleeping.

As a victim of sexual harassment in adolescence, is likely to have an impact not only their emotion but also their academic performance. It made them anxious to go to school, unable to speak in school, inattentive at school, and unmotivated. Generally, the victim prefers to stay at home. It happens to Melinda, who is inactive at school and get a low score because she can't open her mouth to speak to present her work. In other terms, it's difficult to express herself easily in school to give an opinion.

Sexual harassment can have a negative effect on a someone's physical and mental health. The victim frequently stays at home and refuses to speak to anyone. They frequently blame themselves for what happened and try to explain it by claiming that they deserved it in some way. They are depressed, and in many cases, this leads to suicide. For the victim, Sexual harassment can also have longtime effects. In the following of rape and other forms of sexual harassment, posttraumatic stress disorder (PTSD) is usual. Despite the differences in terms, there is no significant distinction between psychological and emotional impact. Emotional describes feelings, whereas psychological describes both emotional and mental aspects. As a result, psychological impact should officially contain both emotional and mental effects. Melinda's tragic experience has left an emotional scar on her, making it difficult for her to express her feelings and communicate with others. On the other hand, psychological effect is a circumstance in which Melinda avoids many people who speak with her. For example, when Melinda tries to escape from her teacher, she met Andy by coincidence in the school hallway, and she then hurried to the school closet to hide her real feelings.

\section{Struggle to express herself because of the traumatic}

Sometimes where someone cannot express herself because of the bad things. Whether it's the big one or not. It will happen in some months or it can be long-lasting. It depends on themselves. Whether they want to overcome it or just want to have a fearful life. But for those who want to struggle to express their self. There are many ways to do it. One of those is through art. Art is frequently defined as a wide range of techniques for expressing one's thoughts and ideas. According to Thomas, Art and creative expression can inspire a tidal wave of emotion, saying what words surely cannot. (2011).

In Melinda's case, she joined to art class. Where Melinda's confession and speech, expressed in art and the planting of trees, brings healing rather than criticism, punishment, or forgiveness. Melinda compares learning to control her imagination like learning a new language. Melinda believes that drawing a tree is simple at first, but the more she tries, the more she realizes that she is unable to do it. Her emotions are overwhelming her. Trees have long been utilized as a symbol for life and death in religions all around the world (Roman, 2014). The source of rebirth is trees. A tree is a symbol for Melinda.

People use techniques to properly deal with life's stresses and problems. They employ the most effective techniques to reach their goals. Their best implement can be called struggle. Popow and Saez stated that struggles may be defined as referring to 
the people to perform their self-expression using education (2016). Every human realizes that they have to struggle because they will be satisfied by their struggles. Deeply, the struggle for life is important to creating one's life purpose and resolving a problem. It's something that we can do with motivation. The study of why individuals believe and behave the way they do is known as motivation. People commonly have intentions and purposes for what they believe or do. These intentions and purposes are calls as motivation. Someone always has their own reasons for accomplishing things and goals.

There are two types of motivations that people have in their life. The first type is intrinsic motivation. It comes from them. According to Legault, he explained that intrinsic motivation refers to engaging in conduct that is naturally pleasant or enjoyable (2016). They do something because it is inherently. And the second type is extrinsic motivation. It tends to refer to doing something because it produces a specific result. Extrinsic motivation refers to behavior that is primarily motivated by the accomplishment of a goal that is unrelated to the action (Legault, 2016). Although the best type of motivation is intrinsic motivation and is related to a number of advantages such as enjoyment, perseverance, and psychological well-being, it is not the only type of motivation. Deci and Ryan defined that extrinsic motivations are sometimes regarded to be useful in encouraging people to accomplish things that aren't intrinsically enjoyable like recycling, doing homework, obeying traffic laws (2008). To put it another way, the desire to encourage or force people to follow socially desirable behavior standards can sometimes conflict with the protection and management of personal freedom and intrinsic motivation.

In art class, Melinda has to learn about the painting of a tree while got motivation from her teacher. And the teacher helped Melinda to build her confidence back. Self-confidence is define as characteristic capability of influencing students' behaviour. Kidwell, Hardesty, and Childers, they argued that feelings can influence confidence (2008). For example, Emotions of disbelief and/or displeasure associated with the thing can reduce confidence, but positive emotions like the emotion of appreciating the things, and also the love and happiness associated with the thing, that may develop confidence.

It can be said that the concept of motivation and self-confidence have important effects on students' behavior. Individuals' effectiveness and efficiency are improved by using motivational factors. As a result, both individually and collectively goals already accomplished. Scientists have been interested in this concept of motivation from all fields concerned with humans. Motivation is The process of starting and maintaining goal-oriented actions is referred to as reward (Cook \& Artino, 2016).

Melinda's struggles from her sexual abuse trauma appears in two motivations: intrinsic and extrinsic. Melinda's intrinsic motivation to overcome her sexual abuse was evident in her participation in class without being forced. It's intrinsically tied to her. Melinda expressed her thoughts on a question given by the teacher. Extrinsic motivation plays a role in Melinda's struggle against sexual abuse. It is proven when Melinda completes a teacher-assigned task. Melinda's teacher instructed her to write a report and deliver it to the class. She finished her project, but she didn't want to show it to a large group of people. She simply hands them the paper and instructs them to read it alone. Clearly, she completed the task in order to increase her grade, not because she enjoys it.

School, as one of the most essential socializing environments, is critical for communication development. Schools are also places where new attitudes and actions originate. It is possible to state that, for student motivation, It is important that the teacher build a range and quality of communication with the student (Lunenburg \& Ornstein, 2012; Önciu, 2005; Tomul, 2006). In psychology, The way 
someone reacts to something which happens to them might reveal a lot about their personality. In psychology, the ability to describe the behavior of a large number of people is necessary.

Art is often described to express one's thoughts, ideas, and actions. It helps us to communicate our thoughts, desires, and conflicts that may develop in our life through the application of our imaginations. The drawings' purpose is unclear, however it is assumed that they served as a means of communication and showed various ceremonies (Morrison, 2017). Creating visual images through drawing is to express our feeling that something can bring us closer to others because art can be proven as a means of communication, and the visual images can have an effect on our thoughts and memory. Transferring memories and ideas into visuals was a helpful tool for victims of traumatic events to help them recover (Hussain, 2010).

She finds someone who can help her express her feelings through art class. Melinda is given the task of creating an art project centered on a tree. Through her painting work, she begins to express her feeling. She designs a sculpture of a skeleton out of dried bones at one point. She then attaches broken knives and forks to the project, making the bones appear to be stabbed by the plastic spoons. It's a complicated picture of Melinda's feelings, and Mr. Freeman praises it right away. Having to create a tree for Mr. Freeman's class hasn't made it difficult for Melinda to communicate what her art really means. He can readily interpret her artworks because they implicitly describe her pain.

It presented ways to better help people comprehend and heal their experiences by combining psychological techniques with the use of visual arts. It allowed therapists to discover new techniques to evaluate someone who was coping with trauma by combining components of psychological processes into the therapeutic art process. Art expression could be beneficial in the treatment of trauma, especially for those who are unable to explain their feelings through words.
According to Pynoos, Clinicians developed protocols that used drawing to help victims of traumatic events express their thoughts, convey details about the trauma event, and recover control over their emotions (1986). Art therapy is defined by the systematic use of art forms such as drawing, painting, sculpture, and carving to form and express feelings, attitudes, and memories.

The most difficult obstacle Melinda must overcome is her struggle to overcome the traumatic experience. Melinda is in terrible condition until she gets a way to deal with her pain and cope with what has happened. She was already raped by her senior and unable to inform the people of the school. So, what we can take from Melinda is that speaking is important. Not only to declare the truth about what happened to ourselves, but also to speak our opinions and stance. This is what Melinda learned from art class in her school. Slowly she mustered up the courage to talk to Rachel over what happened to her. This is also important, because Melinda saw Andy close to Rachel, she is afraid what happened to her could also happen to Rachel. Rachel is a friend she can trust on. Melinda has a chance to heal herself by beginning to express herself and participating in class, even if Rachel does not believe it.

The students told the play therapist that they wanted to use their artwork to communicate their moods and feelings, and they came up with creative ways to do so (Carroll, 2002). Communication and interaction were reached during the expressive art activity. Melinda paints always has a meaning. It's not only about her pain, but it's about the happy moment that she experiences as well. She also began to express feelings of expectation, as well as enhanced self-confidence, in a positive communication environment. Because, the goal of art therapy are reduce the anxiety, increasing of selfconfidence, and provide the communication in positive atmosphere.

\section{CONCLUSION}


Analyzing the character to answer all the questions above, the researcher can conclude that Melinda Sordino as the main character who can't show her self-expression dealing with people around her that had suffering a bad memories of being raped which she felt after attended the party who made her become silent. She also got bullied by her friends because her action called the police without asking the reason of her action. It's because of the sexual harassment that she suffered. The researcher finds out that Melinda has been diagnosed with PTSD. Her trauma made her hard to speak with her friends about her true feelings and being unmotivated. It's also result in Melinda's psychology condition where her behavior is change abruptly. She transforms into a different people who enjoys alone to crowds.

The victim of rapery always becomes a nightmare like Melinda. It is a horrible experience that will be remembered for a long period of time. The traumatic experience made the victim felt shame, guilt, and losing self-confidence. The victim will starts avoid the place or the doer that reminds them about the incident, the flashback also appears to show the traumatic incident. the big support for the victim from their friends and family is needed to heal from the trauma. Even though the traumatic event cannot be forgotten, the victim can begin to move forward and live their lives.

\section{REFERENCES}

Bisson, J. I., Cosgrove, S., Lewis, C., \& Roberts, N. P. (2015). Post-traumatic stress disorder. BMJ (Online), 351(November), 1-7. https://doi.org/10.1136/bmj.h6161

Breitbart, W. (2016). It's a struggle: That's the nature of life. Palliative and Supportive Care, 14(3), 175-176. https://doi.org/10.1017/S1478951516000328

Christiansen, D., Bak, R., \& Elklit, A. (2012). Secondary victims of rape. Violence and Victims, 27(2), 246-262. https://doi.org/10.1891/0886-6708.27.2.246
Elo, S., \& Kyngäs, H. (2008). The qualitative content analysis process. Journal of Advanced Nursing, $\quad 62(1), \quad 107-115$. https://doi.org/10.1111/j.13652648.2007.04569.x

Green, M. (2010). Précis of Self-Expression (Oxford, 2007). Acta Analytica, 25(1), 65-69. https://doi.org/10.1007/s12136-009-0082-0

Gussak, D. E., \& Rosal, M. L. (2015). The Wiley Handbook of Art Therapy. In The Wiley Handbook of Art Therapy. https://doi.org/10.1002/9781118306543

Hansen, L. K., \& Jordan, S. S. (2020). Encyclopedia of Personality and Individual Differences. Encyclopedia of Personality and Individual Differences, 1-5. https://doi.org/10.1007/978-3319-28099-8

Jay Michael Hanes, \& Eleanor Weisman. (2016). Experience and Expression. Education and Culture, 32(2), 64. https://doi.org/10.5703/educationculture.32.2.0 064

Kaptein, M. (2017). The Battle for Business Ethics: A Struggle Theory. Journal of Business Ethics, 144(2), 343-361. https://doi.org/10.1007/s10551-015-2780-4

Kim, H. S., \& Sherman, D. K. (2007). "Express yourself": Culture and the effect of selfexpression on choice. Journal of Personality and Social Psychology, 92(1), 1-11. https://doi.org/10.1037/0022-3514.92.1.1

Kim, H. S., \& Barbara, S. (2015). Culture \& SelfExpression 1 Cultural Variation in the Motivation of Self- Expression Culture \& SelfExpression Cultural Variation in the Motivation of Self-Expression Heejung S . Kim Thai Q . Chu University of California Santa Barbara. January.

Kim, H. S., \& Barbara, S. (2015). Culture \& SelfExpression 1 Culture and Self-Expression Culture \& Self-Expression Culture and SelfExpression Heejung $\mathrm{S}$. Kim Deborah Ko 
University of California Santa Barbara. January 2007.

Kiliç, M. E., KILIÇ, M., \& Durdağı, A. K. A. N. (2021). Motivation in the classroom. Participatory Educational Research, 8(2), 31-56.

Kivy, P. (1978). Thomas Reid and the Expression theory of Art. The Monist, 61(2), 167-183.

Lee, W., Reeve, J., Xue, Y., \& Xiong, J. (2012). Neural differences between intrinsic reasons for doing versus extrinsic reasons for doing: An fMRI study. Neuroscience Research, 73(1), 6872. https://doi.org/10.1016/j.neures.2012.02.010

Legault, L. (2020). Encyclopedia of Personality and Individual Differences. Encyclopedia of Personality and Individual Differences. https://doi.org/10.1007/978-3-319-28099-8

Morrison, A. (2017). The Benefits of Art Therapy with Children Affected by Acute Trauma.

Oney, E., \& Oksuzoglu-Guven, G. (2015). Confidence: A critical review of the literature and an alternative perspective for general and specific self-confidence. Psychological Reports, 116(1), 149-163. https://doi.org/10.2466/07.PR0.116k14w0

Pfeiffer, V. F., \& Sivasubramaniam, S. (2016). Exploration of self-expression to improve L2 writing skills. Per Linguam, 32(2), 95-108. https://doi.org/10.5785/32-2-654

Popow, M., \& Sáez-Rosenkranz I. (2014). Educational struggles and citizenship education. The case of Poland. Paper Knowledge . Toward a Media History of Documents, 280-298.

Ryan, R. M., \& Deci, E. L. (2000). Intrinsic and Extrinsic Motivations: Classic Definitions and New Directions. Contemporary Educational Psychology, 25(1), 54-67. https://doi.org/10.1006/ceps.1999.1020

Smith, J. R. (2011). EIC 's Message Express Yourself.

Snipes, D. J., Calton, J. M., Green, B. A., Perrin, P. B., \& Benotsch, E. G. (2017). Rape and Posttraumatic Stress Disorder (PTSD):
Examining the Mediating Role of Explicit SexPower Beliefs for Men Versus Women. Journal of Interpersonal Violence, 32(16), 2453-2470. https://doi.org/10.1177/0886260515592618

Stuckey, H. L., \& Nobel, J. (2010). The connection between art, healing, and public health: A review of current literature. American Journal of Public Health, 100(2), 254-263. https://doi.org/10.2105/AJPH.2008.156497

Toktas, S., \& Bas, M. (2019). Investigation of the relationship between the self-confidence and motivation of high school students participating school sport contests. Universal Journal of Educational Research, 7(2), 472-479. https://doi.org/10.13189/ujer.2019.070220

Tranquillo, J., \& Stecker, M. (2016). Using intrinsic and extrinsic motivation in continuing professional education. Surgical Neurology International, $7, \quad$ S197-S199. https://doi.org/10.4103/2152-7806.179231

Ueland, B. (2010). If you want to write: A book about art, independence and spirit. Graywolf Press.

Wilt, J. A., Stauner, N., Lindberg, M. J., Grubbs, J. B., Exline, J. J., \& Pargament, K. I. (2018). Struggle with ultimate meaning: Nuanced associations with search for meaning, presence of meaning, and mental health. Journal of Positive Psychology, 13(3), 240-251. https://doi.org/10.1080/17439760.2017.127920 8

Zhou, L., \& Li, M. (2015). Distributive justice climate and job performance: The mediating role of industrial relations climate. Social Behavior and Personality, 43(1), 145-152. https://doi.org/10.2224/sbp.2015.43.1.145 